\section{Norman Leeds, MD}

D $r$ Norman Leeds died on March 5, 2020. Dr Leeds was a key figure in the history of the American Society of Neuroradiology (ASNR). As a young neuroradiologist, he was one of the founding members of the ASNR. With his typical modesty, he once told me that he was made a member because someone had to get the coffee. He was one of the forward-thinking society leaders who was instrumental in the founding of the American Journal of Neuroradiology. His extensive CV attests to his scientific contributions to neuroradiology.

I want to speak of my personal interactions with Dr Leeds and the effect he had on my life. I could say that Norm was my mentor, but he was much more than that. He was the reason that I became a neuroradiologist, and he inspired me to become an academic neuroradiologist. I worked with Norm as a resident at Montefiore Hospital from 1973 to 1976 and as his colleague as an attending from 1977 to 1983. At that time, the radiology department at Montefiore was an interesting place to train. It was led by brilliant but idiosyncratic and mercurial leaders. Most of my coresidents feared working on the neuroradiology rotation because of a combination of demands of the service and Norm's occasional angry outbursts. He once yelled at a resident, "What do you think I'm talking, tuna fish?" Somehow, we knew what he meant. (There were many such "Normanisms." Syntax was not his strong suit). For whatever reason, I was not afraid of Norm, and I enjoyed working with him, learning how to interpret studies and observing his pivotal role in the clinical care of patients with neurologic disorders.

The 1970s was a time of transition for neuroradiology. At the beginning of the decade, cerebral angiography was the definitive diagnostic imaging technique, relied on by neurosurgeons and neurologists. The interpretation of angiograms was extremely difficult, and those individuals who were experts (including Norm) seemed to have an almost mystical talent. Norm would look at an angiogram with the referring clinician, wave his hands in the general direction of the films, and say "Right parietal parasagitta, 1 probably a met, see it?" He was almost always correct. Sometimes I wondered if even he knew how he came to the correct answer.

In the mid-1970s, the introduction of CT revolutionized neuroimaging. Lesions were much easier to see and characterize. Some neuroradiologists feared that this would be the end of our specialty. However, CT was new, and most referring clinicians were unsure about interpretation; therefore, they continued to rely on neuroradiologists. Norm's interactions with referring physicians, in particular neurosurgeons, were inspiring to me. He was a crucial part of the team, respected by and respecting of his clinical colleagues. After my fellowship, I returned to Montefiore to work with Norm. Over the next 6 years, we worked together, and I learned an enormous amount about image interpretation. I learned from him that the most important and satisfying aspect of neuroradiology was the interaction with referring physicians. I also came to
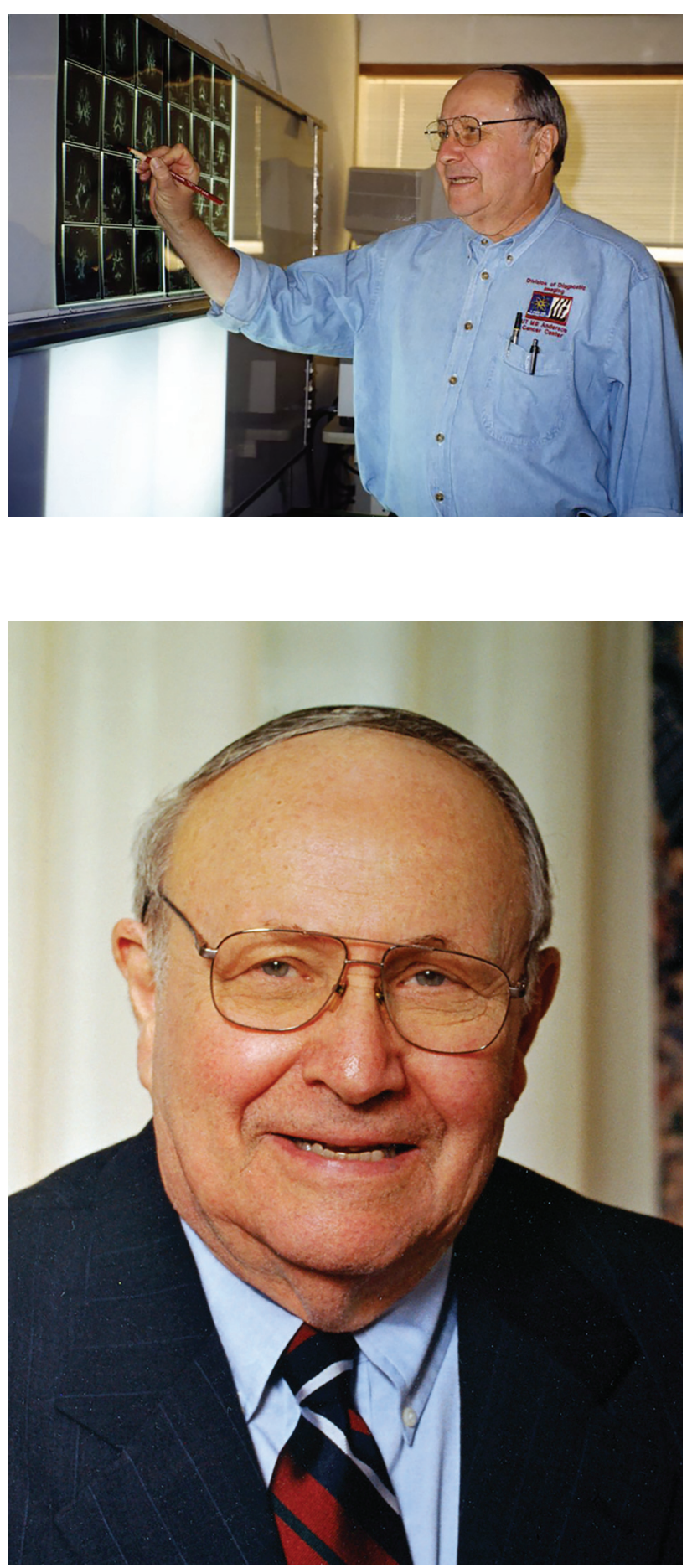

know Norm as an individual. Although he still had a temper, I got to see a side of him that was not so apparent to me as a resident. He was incredibly generous, arranging invitations for me to speak at many institutions even when it meant that he would have to shoulder more of the clinical load. He helped develop my research interests and encouraged me to present our findings at national meetings. His love for and devotion to his wife Betty and his children were amazing to witness.

AJNR Am J Neuroradiol 41:1323-24 Jul 2020 www.ajnr.org 
Following my time at Montefiore, I joined the faculty at New York Hospital and Norm went on to become chairman at Beth Israel Hospital in New York and then the chief of neuroradiology at MD Anderson Cancer Center. I took with me the lessons I learned from Norm. When a clinician would come to the neuroradiology reading room and ask to look at a study, the radiology resident would sometimes view this as an interruption. I explained, as Norm had explained to me, that this was the real work and the real source of job satisfaction. I have tried to inspire my residents the way that
Norm inspired me, pointing out how interesting and fulfilling a career in neuroradiology could be. I think of the many neuroradiologists I have trained as Norm's academic grandchildren.

I remained in contact with Norm throughout the remainder of his career. It amazed me that he continued to learn all the new things that MR imaging had to offer.

I will miss him dearly.

http://dx.doi.org/10.3174/ajnr.A6612
Robert D. Zimmerman, MD, FACR 